\title{
COMMERCIAL ADAPTATIONS OF MECHANICAL STIMULATION FOR THE CONTROL OF TRANSPLANT GROWTH
}

\author{
Lauren Garner and F. Allen Langton \\ Horticulture Research International \\ Wellesbourne \\ Warwick CV35 9EF \\ UK
}

\author{
Thomas Björkman \\ Department of Horticultural Sciences \\ New York State Agricultural Experiment Station \\ Cornell University \\ Geneva, New York 14456 \\ USA
}

Additional index words: brushing, Impatiens holstii, Lycopersicon esculentum, Pelargonium $x$ hortorum, Petunia hybrida, transplant production, Viola tricolor

\section{$\underline{\text { Abstract }}$}

The commercial use of mechanical stimulation to control transplant growth is quite limited. To be commercially successful, the technique must be simple and flexible, and must not reduce plant quality. Brushing was applied to tomato (Lycopersicon esculentum) seedlings growing at a density of 2100 plants $\mathrm{m}^{-2}$ by daily stroking with a piece of polystyrene. Ten or twenty daily strokes typically provided significant height control without plant damage. Increasing the interval between strokes to up to 10 minutes resulted in the same amount of height control as continuous brushing. There were typically no differences between treating the plants at 0800 or at 1700 hours. Significant height control was achieved if treatments were begun at the first or second true leaf stage, but treatments begun at a later stage of development resulted in leaf damage. Brushing before transplanting to the field resulted in a significant decrease in stem elongation $(-20 \%)$. However, there were no significant differences between brushed and unbrushed plants in long-term growth or final fruit yield after transplanting to the field. Preliminary studies were also conducted on four bedding plant species: geranium (Pelargonium $\mathrm{x}$ hortorum), impatiens (Impatiens holstii), petunia (Petunia hybrida) and pansy (Viola tricolor). Brushing was applied to seedlings growing at a density of 1500 plants $\mathrm{m}^{-2}$ using either polythene or plastic netting. For geranium and impatiens, any reductions in plant stature were associated with significant plant damage. Brushing induced a prostrate growth habit and leaf distortion in petunia and significantly reduced leaf area and shoot dry weight. Pansy plants were undamaged by 10 or 20 brush strokes per day and showed a significant (17-22\%) decrease in petiole length, typically without significant effects on leaf area, dry weight or days to flower. Brushing provides a flexible, effective method for controlling tomato and pansy transplant size without adversely affecting quality or long-term growth.

\section{Introduction}

Plug transplants are typically grown at very high plant densities to make transplant production economically viable (Marr \& Jirak, 1990). This close spacing results in an uneven canopy of many elongated plants with weak stems. Delivering a crop of the correct size and proportions at the promised time can be extremely difficult. There is, therefore, a commercial need for treatments which decrease extension growth and 
improve crop uniformity.

Mechanical stimulation (MS) can decrease the rate of stem and petiole elongation of many species (Biddington, 1986; Latimer, 1991). One type of MS which appears suitable for commercial use is brushing but, despite extensive research, its commercial use remains limited. For successful commercial application, the brushing technique needs to be simple and flexible, without delaying or decreasing flower or fruit production.

A series of experiments was conducted using tomato (Lycopersicon esculentum) plug transplants to determine the dosage and timing of brushing necessary for effective height control, and to determine what effect, if any, brushing had on field performance. Research concerning the effects of MS on floricultural crops is considerably more limited than that on vegetable crops, probably due to the availability of chemical growth regulators approved for use on bedding plants. However, the use of growth regulators is expensive and subject to error. Accordingly, preliminary studies were conducted to determine whether brushing can be used commercially to control the size of four bedding plant species, geranium (Pelargonium $\mathrm{x}$ hortorum), impatiens (Impatiens holstii), petunia (Petunia hybrida) and pansy (Viola tricolor).

\section{Materials, Methods, Experiments}

\subsection{Tomato experiments}

Tomato seedlings were grown in plug trays at a density of 2100 plants $\mathrm{m}^{-2}$ as described previously (Garner \& Björkman, 1996). Brushing was applied by gently stroking the canopy back and forth with a piece of polystyrene (Styrofoam).

\subsubsection{Dosage}

Three separate experiments were conducted in which the transplants were brushed 0 , 10,20 , or 40 times back and forth, once a day.

\subsubsection{Timing}

Experiments were conducted to determine whether increasing the time interval between brush strokes resulted in the same amount of height control as continuous brushing. All of the treated plots were given 10 strokes per day, but the time interval between pairs of back and forth strokes was varied. There were four brushing treatments: 0.01 minutes between strokes (continuous stimulation), $0.1,1$ or 10 minutes between strokes.

Growers will probably want to brush plants at the beginning or the end of the work day so as to minimize interference with other production practices. Therefore, experiments were conducted in which plants were brushed 20 times per day either in the morning (between 0800 and 09:00) or the afternoon (between 16:00 and 17:00).

A set of experiments was conducted to determine at what stage of growth brushing should begin. Treatments began when the canopy height was approximately 6,8 , or 10 $\mathrm{cm}$ high, so that plants were at either the first, second or third true leaf stage, respectively. 


\subsubsection{Field performance}

Processing tomatoes were seeded to coincide with the commercial production seasons of 1994 and 1995. Transplants which had either been brushed or untreated while in the glasshouse were then randomly selected and mechanically transplanted to the field at the Fruit and Vegetable Research Farm in Geneva, New York in a completely randomized design. Fruit were harvested by hand in a destructive harvest when the fruit were full size and approximately $50 \%$ were at the red ripe stage.

\subsection{Bedding plant experiments}

Experiments were conducted using geranium, impatiens, petunia and pansy transplants provided by W.J. Findon \& Sons, Stratford-upon-Avon. Brushing was applied to seedlings growing in '165 plug trays' (1500 plants $\left.\mathrm{m}^{-2}\right)$. Flexible materials, including polythene and several gauges of plastic netting, were used to provide the brushing stimulus, as such materials are more easily integrated with production practices. Materials were folded over and secured at the loose end to make the brushing apparatus. Brushing was applied by stroking the canopy back and forth. Treatments were arranged in a randomized complete block design for impatiens, petunia and pansy experiments, and in a completely randomized design for geranium experiments, with a quarter tray used as an experimental unit. Treatments were begun at the cotyledon stage and continued until the plants were large enough to pot on. Further experiments were conducted on those species for which an appropriate material for brushing had been found. Plants were brushed $0,10,20$, or 40 times back and forth, once a day to determine the appropriate dosage of brushing.

\subsection{Statistical Analysis}

Treatment effects were tested by analysis of variance (Schaefer \& Farber, 1992) and individual treatment means were compared by using Fisher's protected least significant difference procedure (LSD) with 95\% confidence level.

\section{Results}

\subsection{Tomato experiments}

The results on dosage and timing summarize work previously described in the Journal of the American Society for Horticultural Science (Garner and Björkman, 1996).

\subsubsection{Dosage experiments}

In two experiments, all three treatments caused significant reductions in stem length relative to untreated plants, though a significant linear trend between the number of brush strokes per day and stem length was only detectable in one experiment at $\mathrm{P}=0.05$ (Table 1). In two experiments, plants receiving 20 or 40 strokes per day had significantly larger stem diameters than those receiving 0 or 10 . Forty strokes per day often resulted in significant shoot dry weight reductions. 


\subsubsection{Timing}

Stem elongation was significantly decreased whatever the time interval between brush strokes (untreated: 0.77 and $0.72 \mathrm{~cm} \mathrm{~d}^{-1}$; treated: 0.59 and $0.56 \mathrm{~cm} \mathrm{~d}^{-1}$ in the two experiments, respectively). Differences in the stem elongation rate among the four brushing treatments were not significant.

Stem elongation was reduced by $28 \%$ with morning treatments and by $20 \%$ with afternoon treatments in one experiment. This difference was significant at $\mathrm{P}<0.05$. In the second experiment there was no significant difference in stem elongation between the morning and afternoon treatments ( $28 \%$ and $27 \%$ less than untreated plants, respectively).

When brushing was begun at different canopy heights, all three treatments resulted in significant reductions in plant height relative to untreated plants. The stem elongation rate of the stimulated plants was the same once brushing began $\left(0.27 \mathrm{~cm} \mathrm{~d}^{-1}\right)$, regardless of the treatment, and was less than half that of the untreated plants $\left(0.59 \mathrm{~cm} \mathrm{~d}^{-1}\right)$. Differences in height at the end of the experiment were, therefore, the result of the length of the treatment period, and not the stage of development at which the treatments began.

\subsubsection{Field performance}

At transplanting, the stem length of brushed plants was $20 \%$ less than untreated plants. However, a long-term reduction in the growth rate as measured by height was not observed (Figure 1) and there was no difference in final yields in either year (Figure 2).

\subsection{Bedding plant experiments}

\subsubsection{Geranium}

Treatments did not begin until after the seedlings had reached the first true leaf stage, as they were not sufficiently rooted before this time. Brushing with flexible materials such as plastic netting did not cause noticeable stem or petiole flexure and did not have a significant effect on plant size (Figure 3). Therefore, plants were also brushed with cardboard, which did cause stem and petiole flexure. Those treatments which significantly reduced plant size also resulted in leaf damage or dislodged the plants from the compost.

\subsubsection{Impatiens}

Brushing with plastic netting resulted in significant reductions in stem length (Figure 4). However, this reduction was accompanied by noticeable leaf damage and highly significant reductions in shoot dry weight and leaf area (data not shown). Impatiens transplants brushed with polythene were not damaged, but differences from untreated plants in stem length, leaf area and shoot dry weight were not significant.

\subsubsection{Petunia}

Brushing resulted in smaller, more prostrate transplants relative to those which were 
untreated, but these differences were difficult to measure due to the rosette growth habit of the plants. As petunia plant size was noticeably decreased by brushing with $20 / 20$ gauge plastic netting, an experiment was conducted to determine the appropriate dosage level for brushing with this material. All three treatments $(10,20$ or 40 strokes per day) caused significant reductions in leaf area and shoot dry weight, but there were no significant differences between the three treatments for either parameter (Table 2).

\subsubsection{Pansy}

As pansy petiole length could be significantly decreased by brushing with $20 / 20$ gauge netting without causing leaf damage, a dosage experiment was conducted. Petiole length was significantly reduced by all three treatments and a significant linear relationship was shown between petiole length and the number of brush strokes per day (Table 2).

On average, the treated plants had a significantly lower leaf area than untreated plants but there was no significant relationship with the number of strokes. A portable chlorophyll meter (SPAD-502, Minolta), which estimates chlorophyll content by comparing light transmission at two wavelengths (Schaper \& Chacko, 1991), demonstrated that the leaves of treated plants were significantly greener than those of untreated plants, and that there was a significant linear relationship between the number of brush strokes per day and the optical density of the leaves.

The treatments also resulted in a significant reduction in dry weight as compared to untreated plants. There was a slight linear trend $(\mathrm{P}<0.1)$ between the number of brush strokes per day and shoot dry weight, with 40 strokes per day resulting in the largest reduction. Twenty strokes per day caused a decrease in root dry weight, but this difference was not significant and did not affect the root to shoot ratio.

Plants which had been brushed 20 times per day, but which had not been sampled for dry weight, were potted up and brushing was discontinued. The onset of flowering was not delayed, and flowers did not appear to be damaged (data not shown).

\section{Discussion}

\subsection{Tomato experiments}

\subsubsection{Dosage}

Although previous research had shown that brushing can significantly decrease the rate of tomato stem elongation (Latimer \& Baden, 1991; Johjima \& Latimer, 1992), the amount of stimulation required to provide effective height control without damaging or over-hardening the plants was unknown. Our studies have shown that the amount of brushing necessary for effective control varies with the growing conditions. The height of plants grown during the commercial season (seeded in April) was well controlled ( $20 \%$ shorter) by 10 strokes per day, but faster-growing plants in the June seeding were only modestly controlled ( $12 \%$ shorter) by 40 strokes per day. Brushing during the commercial season also resulted in significant increases in stem diameter, only a moderate reduction in shoot dry weight and no visible plant damage. The amount of daily brushing needs to be limited so that only as much stimulation as is necessary for 
effective height control is applied to avoid large reductions in shoot dry weight and plant damage.

\subsubsection{Timing}

The time interval between brush strokes can be at least 10 minutes long and still provide the same amount of height control as continuous brushing. Brushing could therefore be easily automated, perhaps by modification of an irrigation boom.

Brushing plants in either the morning or the afternoon resulted in significant reductions in stem elongation, though the response to brushing was not greatly affected by the time of day at which the treatments were applied. Brushing at either time was effective, but the morning is preferred because the plants are then least likely to be wet or wilting.

The stage of growth at which treatment application can begin is easy to identify (canopy closure), and it is not critical that treatments begin on the day that this stage of development is reached. However, when brushing was not begun until the plant canopy was $10 \mathrm{~cm}$ high, many of the large tender leaves were ripped. Growers cannot wait until they have a problem with stretching to begin brushing.

\subsubsection{Field performance}

It was thought that the use of MS could negatively affect field performance. However, the treatments did not affect the speed at which the plants recovered from transplant shock or the rate at which they grew soon after transplanting. Furthermore, the treatments did not delay or damage reproductive growth.

\subsection{Bedding plant experiments}

\subsubsection{Geranium and Impatiens}

It was not possible to significantly reduce geranium and impatiens transplant size without causing plant damage. Not all plant species are responsive to MS (Jaffe, 1973). At this point it is unknown whether geraniums and impatiens are insensitive to MS, or if a method of non-injurious stimulation has yet to be identified for these species.

\subsubsection{Petunia}

The effects of brushing on the leaf area and shoot dry weight of petunia transplants were substantial and significant. These differences may have been caused by a twisting and bending of the leaves, which was observed even at the lowest dosage level. Leaves appear "normal" 4 to 5 days after brushing is discontinued. However, this deformation is unlikely to be commercially acceptable, despite the relatively short recovery time. New methods of brushing for petunias should be investigated.

\subsubsection{Pansy}

It was possible to significantly reduce the petiole length of pansy plants without 
causing noticeable leaf damage or distortion. In the dosage experiment, all 3 treatments caused a reduction in petiole length which was large enough to be of practical importance to the grower (17 to $30 \%$ ), although 40 brush strokes per day caused significant reductions in leaf area and shoot dry weight. Lower application rates demonstrated that pansy plant petiole length can be significantly reduced by brushing without a substantial decrease in leaf area or biomass accumulation, or increase in days to flower. The plants were not noticeably damaged by brushing, and the treatments may serve to increase marketability by intensifying the green coloration of the leaves.

\subsection{Summary}

The commercial adaptation of brushing for both tomato and pansy transplants appears promising. Tomato transplants proved highly sensitive to brushing, but changes in the dosage and timing of the stimulation often did not significantly affect the magnitude of the response. Brushing is an effective and flexible method of height control which results in sturdy, high quality tomato transplants without adversely affecting establishment or yield. This technique is currently being used by several tomato transplant growers in New York State. Though many problems were encountered when attempting to brush geranium, impatiens and petunia transplants, it was possible to significantly decrease pansy petiole length without reducing plant quality. Further experiments are in progress with pansy transplants to investigate the proper timing of brushing, and commercial trials are planned for the summer.

\section{Acknowledgements}

The authors gratefully acknowledge financial support provided by the New York State Tomato Research Association, Hatch Grant NYG632506, a Cornell Graduate Research Assistantship to L.C.G., Horticulture Research International, the Horticultural Development Council, Petersfield, UK and W.J. Findon \& Sons, Stratford-upon-Avon.

\section{References}

Biddington, N.L., 1986. The effects of mechanically-induced stress in plants- a review. Plant Growth Reg. 4: 103-123

Garner, L.C. \& T. Björkman, 1996. Mechanical conditioning for controlling excessive elongation in tomato transplants: sensitivity to dose, frequency and timing of brushing. J. Amer. Soc. hort. Sci. (in press)

Jaffe, M.J., 1973. Thigmomorphogenesis: the response of plant growth and development to mechanical stimulation, with special reference to Bryonia dioica. Planta 114: 143157

Johjima, T. \& J.G. Latimer, 1992. Brushing influences transplant growth and subsequent yield of four cultivars of tomato and their hybrid lines. J. Amer. Soc. hort. Sci. 117: 384-388

Latimer, J.G., 1991. Mechanical conditioning for control of growth vegetable transplants. HortScience 26: 1456-1461

Latimer, J.G. \& S.A. Baden, 1991. Brushing vegetable transplants for height control: survey of cultivar responses. Proc. Plant Growth Reg. Soc. Amer.: 166-167 
Marr, C.W. \& M. Jirak, 1990. Holding tomato transplants in plug trays. HortScience 25: 173-176

Schaefer, R.L. \& E. Farber, 1992. The student addition of MINITAB, Release 8. Addison Wesley Publishing Company, Inc., New York, NY

Schaper, H. and E.K. Chacko, 1991. Relation between extractable chlorophyll and portable chlorophyll meter readings in leaves of eight tropical and subtropical fruittree species. J. Plant Physiol. 138: 674-677 
Table 1 - The effect of the number of brush strokes per day on the height, stem diameter and shoot dry weight of tomato transplants.

\begin{tabular}{|c|c|c|c|c|}
\hline Seeding Date & $\begin{array}{l}\text { Brush } \\
\text { Strokes }\end{array}$ & $\begin{array}{l}\text { Stem Length } \\
\text { (cm) }\end{array}$ & $\begin{array}{l}\text { Stem Diameter } \\
(\mathrm{mm})\end{array}$ & $\begin{array}{l}\text { Shoot Dry } \\
\text { Weight_(mg) }\end{array}$ \\
\hline \multirow[t]{4}{*}{ June 1994} & none & 13.8 & 2.24 & 86 \\
\hline & 10 & 13.5 & 2.28 & 82 \\
\hline & 20 & 13.0 & 2.39 & 78 \\
\hline & 40 & 12.1 & 2.39 & 75 \\
\hline F tests: overall & & NS & $* *$ & * \\
\hline $\begin{array}{l}\text { brushed vs. } \\
\text { untreated }\end{array}$ & & NS & $* *$ & $*$ \\
\hline linear & & $*$ & * & NS \\
\hline LSD & & - & 0.09 & 8 \\
\hline Standard error & & 0.4 & 0.03 & 3 \\
\hline \multirow[t]{4}{*}{ July 1994} & none & 12.5 & 2.44 & 86 \\
\hline & 10 & 10.6 & 2.39 & 72 \\
\hline & 20 & 10.0 & 2.35 & 72 \\
\hline & 40 & 10.2 & 2.36 & 70 \\
\hline F tests: overall & & $* *$ & NS & NS \\
\hline $\begin{array}{l}\text { brushed vs. } \\
\text { untreated }\end{array}$ & & $* *$ & NS & $*$ \\
\hline linear & & NS & NS & NS \\
\hline LSD & & 1.4 & - & - \\
\hline Standard error & & 0.4 & 0.04 & 5 \\
\hline \multirow[t]{4}{*}{ April 1995} & none & 14.2 & 2.34 & 89 \\
\hline & 10 & 11.4 & 2.34 & 68 \\
\hline & 20 & 11.3 & 2.51 & 77 \\
\hline & 40 & 10.6 & 2.52 & 74 \\
\hline F tests: overall & & $* * *$ & $* *$ & * \\
\hline $\begin{array}{l}\text { brushed vs. } \\
\text { untreated }\end{array}$ & & $* * *$ & * & * \\
\hline linear & & NS & $* *$ & NS \\
\hline LSD & & 1.3 & 0.12 & 13 \\
\hline $\begin{array}{l}\text { Standard error } \\
\overline{\mathrm{NS}}, * * *, * * * \\
\mathrm{P}<0.001,0.01 \\
\text { Fisher's protected } \\
\text { and on } 20 \text { error }\end{array}$ & ts with & -0.4 & $\begin{array}{l}0.04 \\
\text { significant qua } \\
\text { sgrees of freedon }\end{array}$ & $\begin{array}{l}\text { or significant } \\
\text { atic trends. } \\
\text { in June and Jul }\end{array}$ \\
\hline
\end{tabular}


Table 2 - The effect of the number of brush strokes per day on the growth of petunia and pansy transplants.

\begin{tabular}{|c|c|c|c|c|c|c|c|}
\hline \multirow[b]{2}{*}{ Brush strokes } & \multicolumn{2}{|l|}{ Petunia } & \multicolumn{5}{|l|}{ Pansy } \\
\hline & $\begin{array}{l}\text { Leaf } \\
\text { Area } \\
\left(\mathrm{mm}^{2}\right)\end{array}$ & $\begin{array}{l}\text { Shoot } \\
\text { dry } \\
\text { weight } \\
\text { (mg) }\end{array}$ & $\begin{array}{l}\text { Petiole } \\
\text { length } \\
(\mathrm{mm})\end{array}$ & $\begin{array}{l}\text { Leaf } \\
\text { Area } \\
\left(\mathrm{mm}^{2}\right)\end{array}$ & $\begin{array}{l}\text { Shoot } \\
\text { dry } \\
\text { weight } \\
\text { (mg) }\end{array}$ & $\begin{array}{l}\text { Root } \\
\text { dry } \\
\text { weight } \\
(\mathrm{mg})\end{array}$ & $\begin{array}{l}\text { SPAD } \\
\text { reading } \\
\dagger\end{array}$ \\
\hline none & 796 & 24 & 16.7 & 1170 & 70 & 16 & 36 \\
\hline 10 & 679 & 21 & 13.9 & 992 & 63 & - & 38 \\
\hline 20 & 623 & 19 & 13.1 & 1001 & 63 & 12 & 39 \\
\hline 40 & 621 & 20 & 11.6 & 863 & 55 & - & 40 \\
\hline $\begin{array}{l}\text { F tests: } \\
\text { overall }\end{array}$ & $* *$ & $*$ & $* * *$ & * & $*$ & NS & $* * *$ \\
\hline $\begin{array}{l}\text { brushed vs. } \\
\text { untreated }\end{array}$ & $* *$ & $* *$ & $* * * *$ & $* *$ & $*$ & - & $* * *$ \\
\hline linear & NS & NS & $*$ & NS & NS & - & $*$ \\
\hline LSD & 97 & 3 & 1.7 & 171 & 9 & - & 1 \\
\hline $\begin{array}{l}\text { Standard } \\
\text { error }\end{array}$ & 36 & 1 & 0.6 & 51 & 3 & 1 & 1 \\
\hline $\begin{array}{l}\overline{\mathrm{N}} \overline{\mathrm{S}}, \\
\mathrm{P}<0.001,0.01 \\
\text { Fisher's protecte } \\
\dagger \text { For explanatic }\end{array}$ & $\begin{array}{l}\text { ain effe } \\
\text { LSD }\end{array}$ & withir & $-1-4$ & $\begin{array}{l}\text { ificar } \\
\text { o sig }\end{array}$ & $\begin{array}{l}\bar{P}=0 \\
\text { icant qu } \\
\text { of free }\end{array}$ & ratic & $\begin{array}{l}\text { ficant at } \\
\text { ids. }\end{array}$ \\
\hline
\end{tabular}


Growth rate

(cm/day)

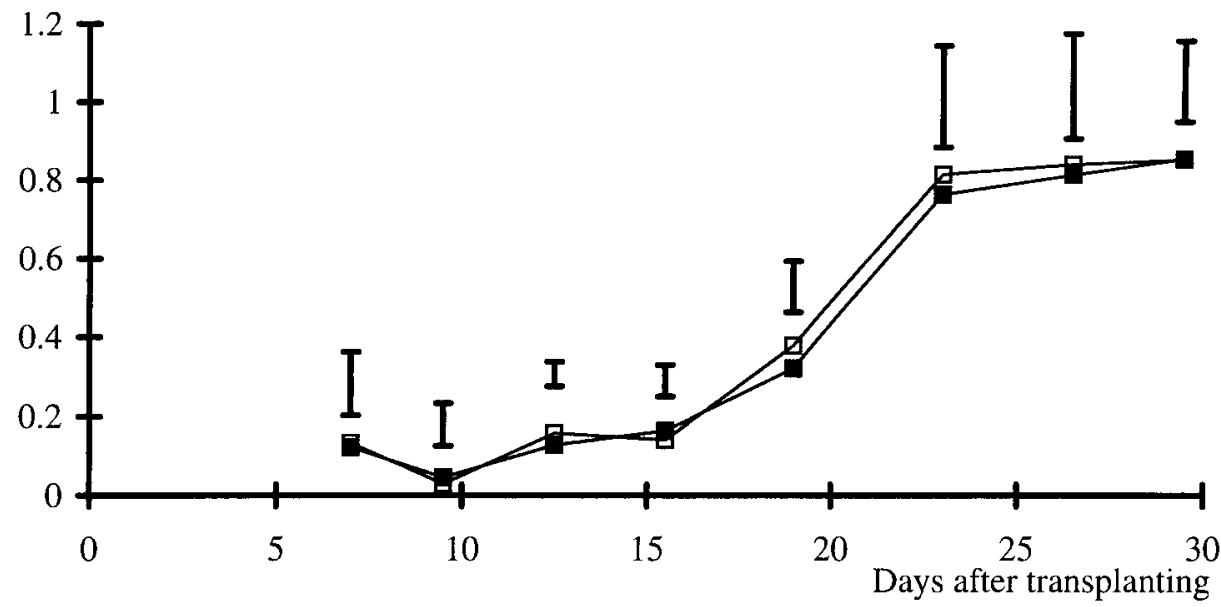

Figure 1 - The effect of brushing on tomato stem elongation after transplanting to the field. The bars represent the LSD based on 7 error degrees of freedom.

$\rightarrow$ untreated $\rightarrow$-brushed

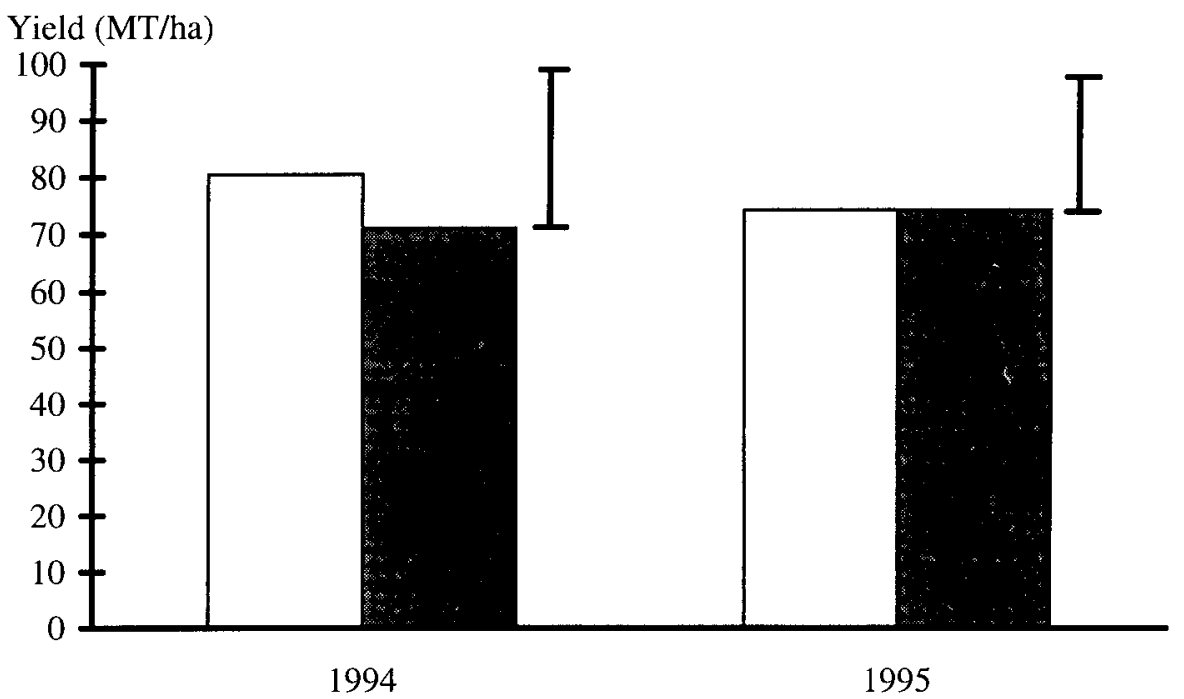

Figure 2 - The effect of brushing on the yield of tomato transplants. The bars represent the LSD based on 7 or 8 error degrees of freedom, respectively. 


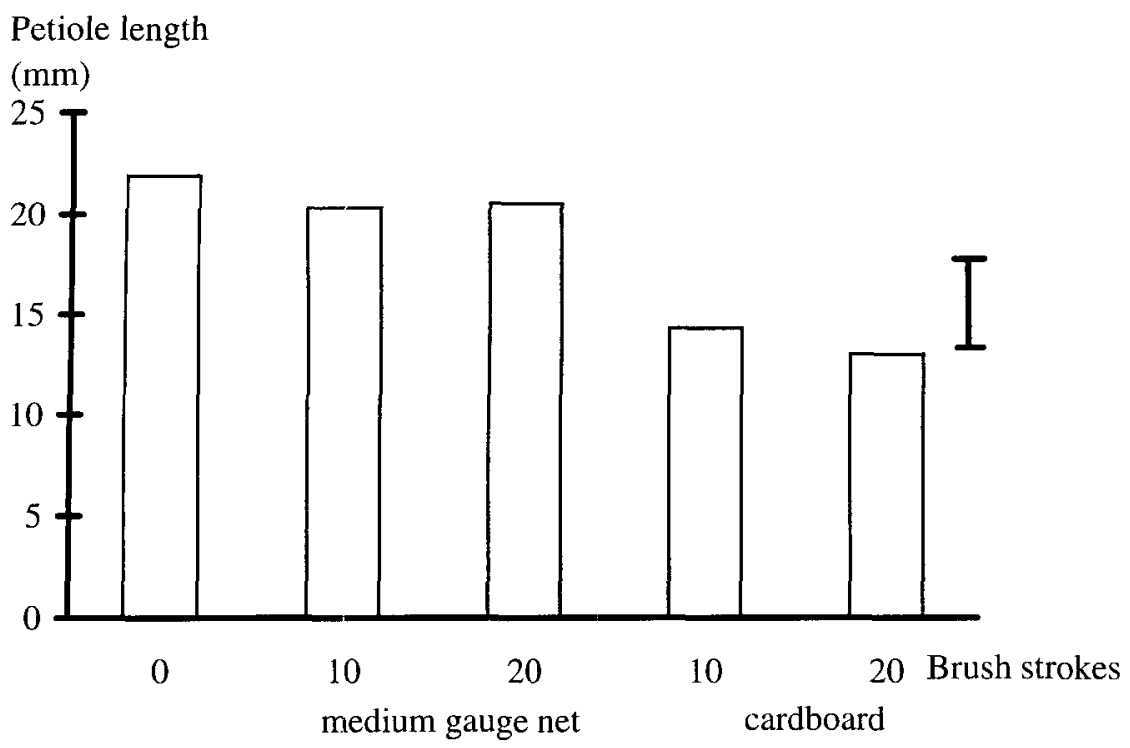

Figure 3 - The effect of brushing on geranium petiole length. Plants treated with cardboard were characterised by severe plant damage. The bar indicates Fisher's protected LSD based on 15 error degrees of freedom with $95 \%$ confidence level.

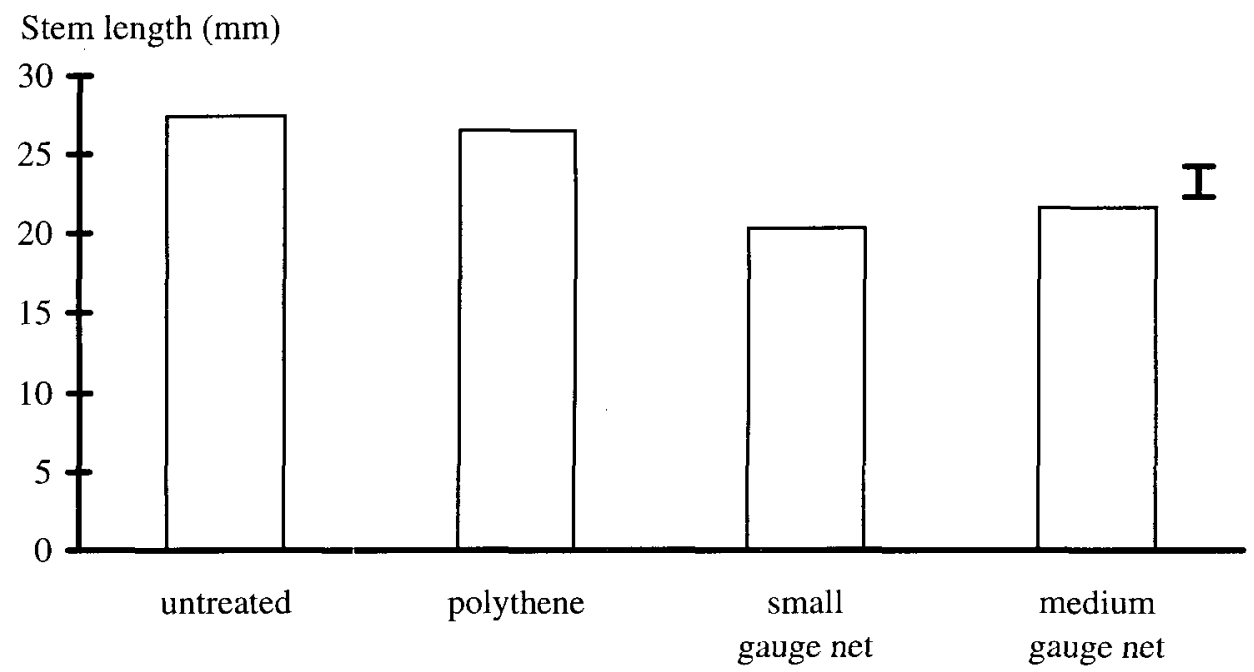

Figure 4 - The effect of brushing on impatiens stem length. Plants treated with netting were characterised by severe plant damage. The bar indicates Fisher's protected LSD based on 15 error degrees of freedom with $95 \%$ confidence level. 